\title{
Enzymatic vitreolysis with recombinant tissue plasminogen activator for vitreomacular traction
}

This article was published in the following Dove Press journal:

Drug Design, Development and Therapy

27 November 2015

Number of times this article has been viewed

\section{Dorota Raczyńska' \\ Paweł Lipowski' \\ Katarzyna Zorena ${ }^{2}$ \\ Andrzej Skorek ${ }^{3}$ \\ Paulina Glasner'}

'Department of Ophthalmology, Medical University of Gdańsk, Poland; ${ }^{2}$ Department of Immunobiology and Environment Microbiology,

Medical University of Gdańsk, Poland; ${ }^{3}$ Department of Otolaryngology, Medical University of Gdańsk, Poland

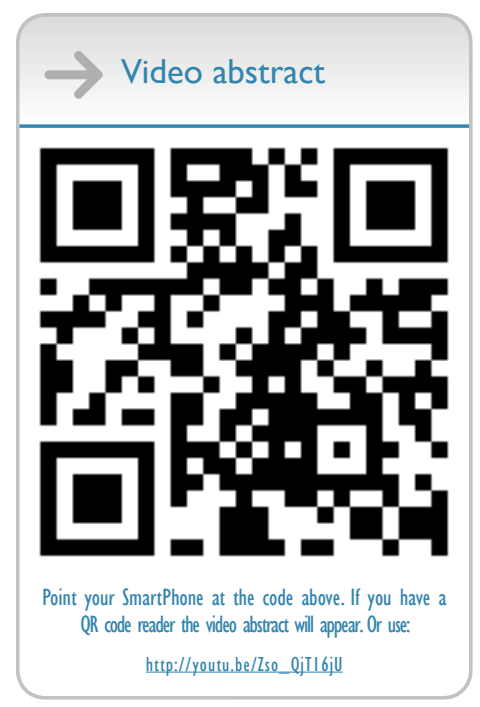

Correspondence: Dorota Raczyńska Department of Ophthalmology, Medical University of Gdańsk, Smoluchowskiego 17, 80-952 Gdańsk, Poland

Tel +48583493580

Email dorotaraczynska@gumed.edu.pl
Aims: The aim of our research was to gain data about the efficacy of intravitreal injections of a recombinant tissue plasminogen activator (rTPA) in dissolving vitreoretinal tractions (VRTs).

Materials and methods: The study group consisted of patients of our Ophthalmology Clinic who had received an injection of rTPA (TPA Group) for an existent vitreomacular traction confirmed by optical coherence tomography and stereoscopic examinations. The control group consisted of patients who had declined treatment despite the existence of a vitreomacular traction confirmed by the same diagnostic methods. Each group consisted of 30 people (30 eyes). The observation period was 6 months.

Conclusion: In both groups some of the VRTs had dissolved. In the TPA group the traction dissolved in 10 patients (33.33\%) and in the control group only in $5(16.67 \%)$. It is also important to point out that the mean baseline membrane thickness was higher in the TPA group than in the control group. Observing patients in both groups we noticed that the dissolution of vitreoretinal membrane occurred most frequently in those cases where the membrane was thin. In the TPA group, the mean membrane thickness after 6 months decreased considerably. At the same time, no significant change in the membrane thickness could be observed in the control group. Observation of the retinal thickness allows us to draw the following conclusion: in the TPA group, the retinal thickness in the macular area (edema) had decreased over the study period, whereas in the control group it had increased. In those cases where the traction had dissolved, the edema of the retina decreased by the end of the 6-month period in both groups. In the TPA group, the dissolution of the membrane occurred most often within 3 months from the primary injection. Based on statistics, we can confirm that in the control group there was a decrease in visual acuity during the 6 months of the study period. At the same time, visual acuity in the TPA group underwent a small improvement. A 6-month observation had shown that in patients with strong VRTs, and in particular with VRTs accompanied by epiretinal membranes, a single intraocular injection is not enough to achieve posterior vitreous detachment. We have also shown that rTPA is a safe drug, with no adverse effects observed during the study period.

Keywords: tissue plasminogen activator (rTPA), vitreous body, macular hole, vitrectomy, epiretinal membrane, diabetic retinopathy

\section{Introduction}

The weakening of vitreoretinal adherence result in posterior vitreous detachment (PVD). Vitreolysis without an accompanying weakening of vitreoretinal adherence results in emerging tractions. If the traction appears within the peripheral part of the retina, then it causes a rhegmatogenous retinal detachment. If it appears within the macula, then it causes a vitreomacular traction (VMT) syndrome or a macular hole. If the vitreous traction is strong enough, then it leads to a local retinal detachment between the retinal pigmented epithelial (RPE) and the neurosensory layer. It results from RPE (as well as 
the choroid) being developmentally part of an ectoderm while the photoreceptors belong to the neuroectoderm. For retinal detachment to occur, the traction force of the vitreous must be strong enough to overcome the three forces "glueing" the retina to the choroid: 1) "intertwining" of the photoreceptors with the projections of the RPE cells, 2) the "suction" force, ie, the RPE pump creating negative pressure in the subretinal space, and 3) the mucopolysaccharide "glueing" forces between the sensory retina and the RPE. ${ }^{1}$

VMT syndrome was described for the first time by $\mathrm{Jaffe}^{2}$ in 1967 as partial peripheral detachment of the vitreous with preserved posterior attachment to the macula. Adhesion between the hyaloid membrane and the retina can occur in any given area of the latter; however, it most often occurs in the posterior pole of the eyeball, including the macula (VMT syndrome) and the optic disc areas. As the vitreous gradually constricts (syneresis), traction on the retina appears. Such adhesion causes the appearance of traction forces both in the antero-posterior and in the tangential planes. ${ }^{3}$ The course of the disease is largely determined by the traction placement (focal or wide-based) and by the degree of PVD. Membrane traction within the fovea most often results in macular edema, and may even lead to the development of a macular hole. Vitreal tractions within the peripheral retina may result in holes, most often horseshoe shaped.

\section{Histology}

Electron microscopy of the vitreoretinal tractions (VRTs) revealed that they consisted mostly of fibrous astrocytes, with accompanying fibrocytes, myofibroblasts, inner limiting membrane (ILM) fragments, collagen, and single macrophages. ${ }^{4}$ No RPE cells were observed.

\section{Etiology}

The VMT syndrome is observed in the case of: incomplete PVD and in vitreoretinal proliferations (PVRs), eg, in the course of diabetes, after massive retinal detachment, injuries, and eye inflammations. It is suspected that during an incomplete PVD (vitreoschisis) there is cell migration from deeper layers of the retina with their proliferation on the vitreoretinal border, due to micro-injuries to the retina. This could be a defensive reaction of the retina to the traction of a constricting vitreous body. Another theory assumes that VRT develops as a result of previous accumulation of retinal cells in the inner layers. It is supposed that this causes stronger adherence between ILM and the posterior vitreous membrane. ${ }^{5}$

Fibrous vitreoretinal proliferations (PVR) seen in the course of diabetes, as well as in other diseases accompanied by retinal hypoxia, are accompanied by new vessels appearing on the pathological membranes and optic disc as well as in other parts of the retina. PVRs are strong, glial tractions, their spread and constriction resulting in antero-posterior and "bridge" tractions of the retina. This process leads to rhegmatogenous retinal detachment, and without treatment, to complete detachment and loss of vision. It should be stressed here that the PVR-type VRT is much stronger, the membrane thicker, and the course of the disease more severe.

VMT syndrome is often accompanied by the presence of an epiretinal membrane (ERM). ${ }^{6}$ This situation leads both to horizontal corrugation of macular structures and to additional traction from the vitreous body. The latter often encompasses both the optic disc and the fovea. The macula then becomes edematous, may detach itself, and a hole may develop. With the coexistence of VMT and ERM, the incidence of full-thickness macular hole is greater. ${ }^{7}$ Spontaneous regression of tractions is rare but possible and depends on the membrane properties.

\section{Symptoms}

VMT symptoms include reduced visual acuity, metamorphopsia and sometimes double vision.

\section{Diagnosis}

The presence of subtle tractions within the macula can easily be overlooked during a fundoscopy, ultrasound examination or in a fluorescein angiography (FLA). It is much easier to detect PVR membranes, even by ophthalmoscopy, as they are thicker, tractions stronger and often vascularized. The same applies to macular pucker (ERM) and traditional retinal detachment. Unlike ERMs, VMT more often lead to leaks in the optic disc, visible in the FLA. ${ }^{8}$ VMT may be suspected if we can see macular edema. In such cases we should see a fluorescein leak in the FLA. In cases of ERM, the most precise diagnostic tool for VMT is the optical coherence tomography (OCT). With the availability of 3D scans we presently have the best possible view of the delicate vitreoretinal structures.

\section{Treatment of VMT}

In the advanced proliferative processes the method of choice is pars plana vitrectomy (PPV), enzymatic vitreolysis (Table 1) and indirectly, systemic pharmacotherapy that is used less often. Pharmacotherapy of PVR consists of controlling inflammation (dexamethasone), decreasing cell adherence to membranes (heparin), and limiting cell proliferation (irradiation, colchicine, daunomycin, and 5-fluorouracil). Pharmacotherapy regimens used for PVR are Heparin + Dexamethasone, ${ }^{9}$ 
Table I Summary of enzymatic substances used in vitreoretinal procedures ${ }^{13}$

\begin{tabular}{|c|c|c|c|c|}
\hline Enzymes & Characteristics & Action point & Assumed safe dose & Indications \\
\hline Plasmin & Non-specific protease & $\begin{array}{l}\text { - Lamin } \\
\text { - Fibronectin }\end{array}$ & $0.4 \mathrm{IU}$ & $\begin{array}{l}\text { - PVD induction } \\
\text { - Macular hole } \\
\text { - Diabetic macular edema }\end{array}$ \\
\hline Hyaluronidase & Specific enzyme & - Hyaluronate & I0, 20 IU & $\begin{array}{l}\text { - Synchysis with partial PVD } \\
\text { - Non-absorbable hemorrhages } \\
\text { to the vitreous }\end{array}$ \\
\hline Dispase & Non-specific protease & $\begin{array}{l}\text { - Collagen type IV } \\
\text { - Fibronectin }\end{array}$ & $0.1-5 \cup$ & $\begin{array}{l}\text { - PVD induction } \\
\text { - Macular pucker } \\
\text { - PVR }\end{array}$ \\
\hline Chondroitinase & Specific enzyme & - Chondroitin sulfate & $20-10,000 \mathrm{U}$ & $\begin{array}{l}\text { - PVD induction } \\
\text { - Epiretinal membranes } \\
\text { - Macular hole }\end{array}$ \\
\hline Collagenase & Specific enzyme & - Collagen & I $2-24 \mathrm{U}$ & $\begin{array}{l}\text { - Easier removal of proliferative } \\
\text { fibrous membranes }\end{array}$ \\
\hline Urokinase & Specific enzyme & - Plasminogen & $\mathrm{I}, 000 \mathrm{IU}$ & - PVD induction \\
\hline TPA & Specific enzyme & $\begin{array}{l}\text { - Peptide bond } \\
\text { - Arginine } 560 \text {-valine } \\
\quad 561 \text { of plasminogen }\end{array}$ & $25-50 \mathrm{mg} / \mathrm{mL}$ & $\begin{array}{l}\text { - Eases PVD } \\
\text { - Intravitreal hemorrhage } \\
\text { - Subretinal hemorrhage } \\
\text { - CRVO (central retinal vein } \\
\text { occlusion) }\end{array}$ \\
\hline
\end{tabular}

Abbreviations: PVD, posterior vitreous detachment; PVR, posterior vitreoretinal proliferations; TPA, tissue plasminogen activator.

Daunomycin, ${ }^{10}$ and LMW Heparin + 5-fluorouracil. ${ }^{11}$ Other proposed therapies include immunosuppressants, cytotoxic drugs, eg, Vit 100 (immunosol), PCNA (proliferating cell nuclear antigen). Additionally, intra-operative injections with mixtures of heavy silicone oils help to treat against PVRs. ${ }^{12}$ The only enzyme currently approved for VMT treatment is ocriplasmin (Jetrea) (ThromboGenics, Leuven, Belgium). Ocriplasmin is a fragment of human plasmin manufactured by genetic recombination techniques in Pichia pastoris yeast. Plasmin injections have been used for a considerable time (prior to vitrectomy for PVD they were used in the treatment of diabetic macular edema (DMO) and stage III macular holes). However, the process of plasmin manufacturing itself is a long and costly one, and the enzyme is labile (short-lived). This fuelled efforts to produce a new enzyme - microplasmin. The MFVI (Microplasmin For Vitreous Injection) trial produced promising results. After the administration of ocriplasmin closure of macular hole was achieved in $40.6 \%$ of eyes as compared with only $10.6 \%$ of eyes treated with a placebo. VMA traction receded by day 28 in $26.5 \%$ of patients given ocriplasmin compared with $10.1 \%$ in the placebo-treated group. Also, compared with the control (placebo) group, total PVD was achieved in a significantly higher percentage of ocriplasmin-treated patients by day 28 .

\section{Enzymatic vitreolysis}

The aim of enzymatic vitreolysis is to liquefy the vitreous (synchysis) and to facilitate PVD by breaking bonds between
ILM and vitreous cortex (syneresis). These processes should be concomitant.

One of the classifications of enzymes used for pharmacological vitrectomy was proposed in 1998 by Sebag. ${ }^{14}$ He divided the enzymes into those acting specifically on a given substrate (eg, chondroitinase, hyaluronidase, and collagenase) and those acting non-specifically, eg, plasmin and dispase.

Sebag, ${ }^{15}$ who has been pursuing the subject of vitreolysis for years, underlines that the future of this non-invasive technique may lie in combination therapy.

\section{Endogenous TPA}

Tissue plasminogen activator (TPA) occurs naturally in the tissues of the eye, such as the vitreous humor and vitreous body. ${ }^{16}$ The role of TPA in the aqueous humor is to lyse the fibrin, which forms during inflammatory processes in the eye. The breakdown of the eye-blood barrier manifests itself through an increased concentration of fibrinogen, which is converted to fibrin with the aid of thrombin. Endogenous TPA deficiency results in a build-up of deposits. Fibrin may deposit in the posterior lenticular capsule (after an implantation of an artificial intraocular lens) and can lead to a secondary cataract, or it may deposit in the iridocorneal angle resulting in glaucoma.

In trials investigating the proteolytic activity of ERMs, both TPA and urokinase were detected. ${ }^{17}$ Thanks to the concomitant production of intercellular matter and the proteolytic 
activity of enzymes, the glial membranes are continuously growing and remodeling.

\section{The use of rTPA in ophthalmology}

Recombinant tissue plasminogen activator (rTPA) (Actilyse, manufactured by Boehringer Ingelheim Pharma KG, Ingelheim, Germany) is a specific serin protease. TPA converts plasminogen to plasmin due to its ability to break a peptide bond between arginine 560 and valine 561. This enzyme acts specifically in the presence of fibrin. ${ }^{18}$ rTPA has been used in ophthalmology for years. As early 1989 Johnson et al $^{19}$ described intravitreal rTPA injections as effective in hemorrhages into the vitreal cortex. The enzyme is widely used in the treatment of subretinal hemorrhages, ${ }^{20-22}$ fibrous membranes in the anterior chamber, ${ }^{23,24}$ thrombi, ${ }^{25,26}$ intravitreal hemorrhages in silicone oil filled eyes, ${ }^{27}$ in maintaining patency of iridectomy, ${ }^{28}$ and in fibrinolysis of fibrous deposits within implants. ${ }^{29,30}$ It has also been used for achieving PVD. ${ }^{31}$ PVD is particularly important in patients with DMO. In DMO as well as in thrombi accompanying vitrectomy great emphasis is placed on meticulous removal of the vitreal cortex. ${ }^{32-35}$ It is assumed that PPV prevents retinal hypoxia. ${ }^{36}$

\section{Materials and methods Patient selection}

\section{Study group}

The study group consisted of patients of our Ophthalmology Clinic (Ophthalmology Department Medical University in Gdańsk), who had received an injection of rTPA (TPA Group) for an existent VMT confirmed by OCT and stereoscopic examination of the posterior segment of the eye.

\section{Control group}

The control group consisted of patients who had declined treatment despite the existence of a VMT confirmed by the same diagnostic methods. They only agreed to their disease being monitored.

Each group consisted of 30 persons (30 eyes).

All patients gave an informed consent to participation and possible treatment.

Patients in both groups had to fulfill the following diagnostic criteria:

Inclusion criteria: age - above 18 years of age, diagnosis confirmed by specialist ophthalmological examination, an informed consent form having been signed.

Exclusion criteria: proliferative diabetic retinopathy, visual acuity below 0.1 on Snellen chart, pregnancy or lactation, hypersensitivity to the active substance or to any of the excipients, active systemic inflammatory process as well as inflammation of the eye, patients with intravitreal hemorrhage, ophthalmoscopic procedure within the last 3 months. Other excluding factors were high myopia, peripheral degeneration of the retina, neoplastic changes of the eyeball and adnexa oculi, optical media opacity preventing eye evaluation in the OCT, patients with unstable ciliary zone, ill-controlled glaucoma (defined as intraocular pressure $>26 \mathrm{mmHg}$ despite treatment) or retinal detachment.

Tests used for statistical analysis were performed six times: on days 0 (day of injection), 7, 14, and 28, as well as after 3 and 6 months. The study period was 6 months. For the TPA Group day 0 was the day of intravitreal rTPA injection. Patients taking antithrombotic agents were advised to withdraw them for 7 days prior and we also sought to normalize blood pressure in patients with hypertension. All participants had a distance visual acuity test using Snellen charts, with best lens correction, slit-lamp examination of the anterior eye chamber as well as eye fundus and intraocular pressure measurement. The measurement of retinal thickness and thickness of the membrane participating in the VRT in the fovea was taken by Carl Zeiss Meditec Stratus OCT 3000.

\section{Performing intravitreal rTPA injection}

Actilyse (Boehringer Ingelheim) $20 \mathrm{mg}$ dry substance was dissolved in $20 \mathrm{~mL}$ of Sol-Ophthal solvent and divided into single doses. Syringes with dissolved drug were frozen to $-70^{\circ} \mathrm{C}$. The dissolution and storage procedure had been described previously in the literature. ${ }^{37,38}$ Before administration, the drug was re-warmed to room temperature. After disinfection of the eyelids and the conjunctival sac with Povidone Iodine solution, and topical anesthesia with proxymetacaine hydrochloride (Alcaina), $0.1 \mathrm{~mL}$ (ie, $50 \mu \mathrm{g}$ ) of the rTPA preparation was injected intravitreously using an insulin needle, 3.5-4 mm from the corneal limbus.

The research project was approved by the Independent Bioethics Committee of the Medical University in Gdansk (resolution No NKEBN/56/2010).

\section{Statistics}

Statistical calculations were performed using the StatSoft, Inc. (2010) STATISTICA (data analysis software system), version 9.1, www.statsoft.com, and Excel calculation sheet.

\section{Sex}

The chi-square test revealed no statistically significant sex differences between groups (chi-square value: 0.0667408, $P=0.7961$ ). Sex distribution in both groups was similar. 


\section{Age}

In the TPA group, the average age was 66.47 (SD 8.90) years, and in the control group 69.77 (SD 9.67) years (medians: 68 and 72 years, respectively). The age in both groups was from a population of normal distribution. The Student's $t$-test showed no statistically significant age differences between the groups (Student's $t$-test value: $1.375874, P=0.1742$ ). In both groups, the age was similar.

\section{Membrane thickness}

In the TPA group, the average membrane thickness decreased significantly (Student's $t$-test value: $3.278675, P=0.0029$ ) while in the control group no statistically significant differences in membrane thickness were seen (Student's $t$-test value: $1.049412, P=0.3027$ ).

Results were also obtained from the analysis of variance (ANOVA) using the division into two groups (TPA and control) and the time of membrane thickness measurement (at baseline and after 6 months). We obtained statistically significant differences in membrane thickness and the time of measurement (ANOVA value for time variable: 11.309, $P=0.0013$, for group variable: $2.955, P=0.0911$ and for the (time + group) variable: $4.842, P=0.0319$ ). The above results indicate that time and (time + group) variables have significant impact on membrane thickness. By performing post hoc tests (Tukey's test), we obtained results similar to the above Student's $t$-tests, the only statistically significant differences were those for the TPA group: the membrane thickness decreased significantly $(P=0.0017)$.

\section{Diseases}

In both groups most people were affected with diabetes (TPA $-60.0 \%$, control - 53.3\%) (Figure 1).

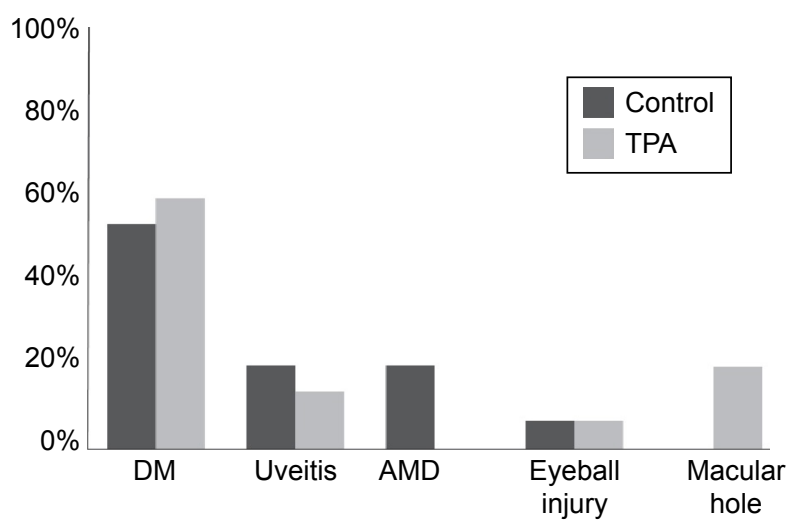

Figure I Percentage distribution of disease incidence in the TPA and control groups. Abbreviations: DM, diabetes mellitus; AMD, age-related macular degeneration; TPA, tissue plasminogen activator.

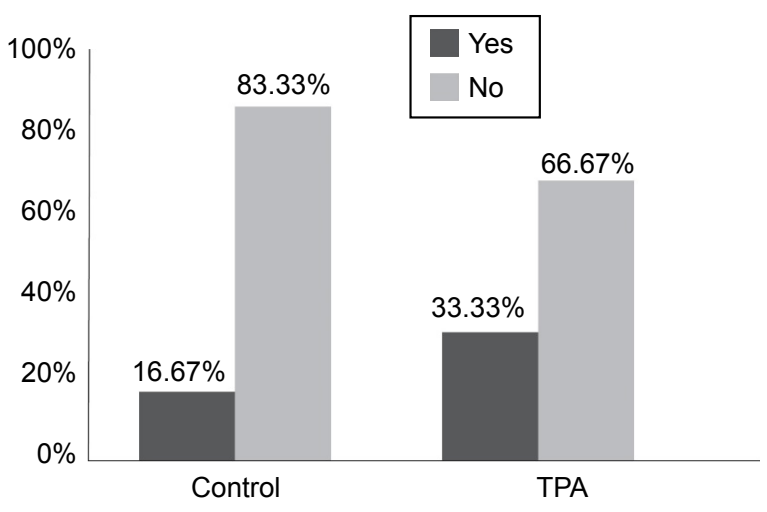

Figure 2 Percentage distribution of traction dissolution in the examined groups. Abbreviation: TPA, tissue plasminogen activator.

\section{Vitreoretinal traction}

In the TPA group there were ten participants with dissolved traction (33.3\% of the group) while in the control group 5 (16.7\%) (Figures 2 and 3).

In the TPA group traction dissolution occurred mostly within the first half of the study period, ie, up to 3 months from the drug injection.

\section{Membrane dissolution and retinal thickness}

To investigate whether retinal thickness had changed in the examined groups, we performed a paired Student's $t$-test. In the TPA group, the retinal thickness decreased significantly ( $t$-test value $3.956708, P=0.0042$ ). Similar results were obtained for the control group ( $t$-test value 3.744602 , $P=0.0200$ ).

In both the tested and control groups, there was a decrease in macular edema after 6 months when the VRT had been dissolved.

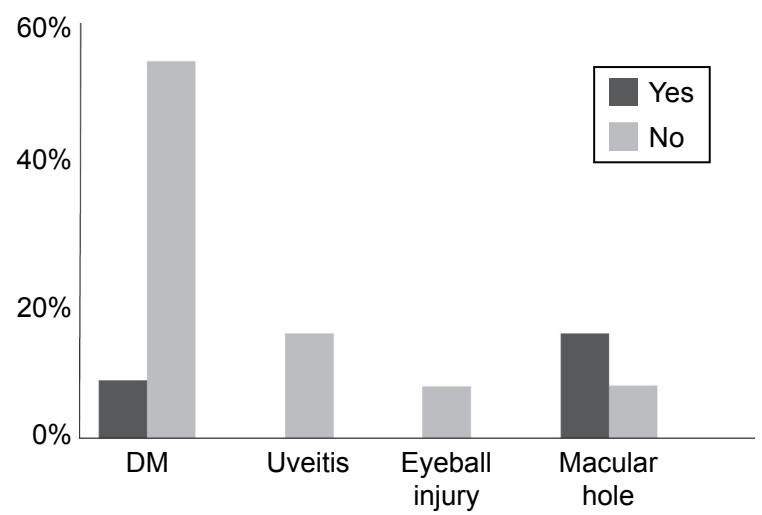

Figure 3 Percentage distribution of traction dissolution in the TPA group depending on disease.

Abbreviations: DM, diabetes mellitus; TPA, tissue plasminogen activator. 


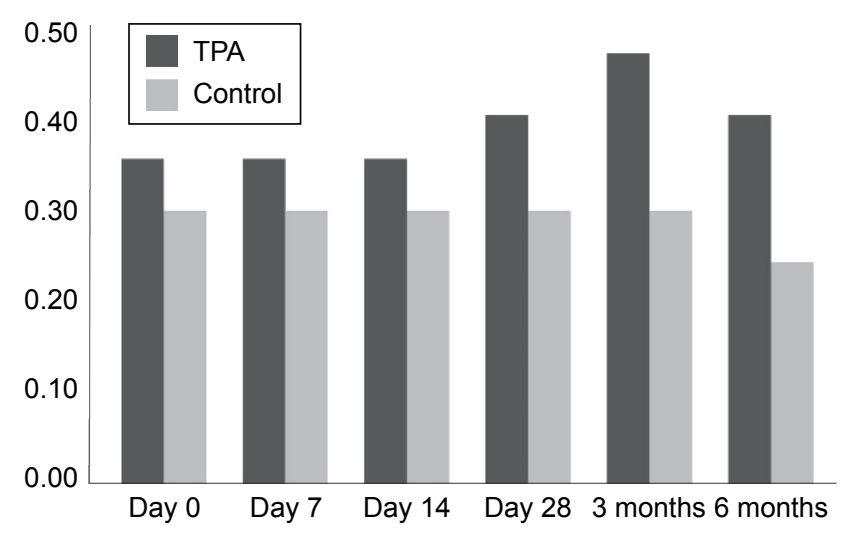

Figure 4 Median of visual acuity in the examined groups in particular time lapses. Notes: The U Mann-Whitney test showed no statistically significant differences in the median visual acuity between the examined groups for any given time lapses. Abbreviation: TPA, tissue plasminogen activator.

\section{Thickness of the membrane participating in the VRT and its ability to dissolve}

The performed analysis has shown that the average membrane thickness allowing an expected traction dissolution is $43.67 \mu$ (SD 7.35).

\section{Visual acuity}

To test the significance of visual acuity differences between groups we performed a chi-square test comparing visual acuity for particular time lapses (Figure 4).
Calculations allow us to conclude that in the control group visual acuity decreased within 6 months from the beginning of the trial while in the TPA group the visual acuity improved slightly.

\section{Intraocular pressure}

A Friedman Test showed statistically significant differences in the median intraocular pressures for particular time lapses (test value $87.96554, P=0.0001$ ). The results showed that despite the increase in intraocular pressure after injection (day 0) this was only temporary and underwent normalization within 2 weeks from the drug administration (Figures 5 and 6).

\section{Discussion}

One of the main aims of vitrectomy is to remove most of the vitreous body. It is of particular importance that a vitrectomy is performed for PDR, PVRs presence, macular peeling, rhegmatogenous retinal detachment, or cortical intravitreous hemorrhage. Mechanical vitrectomy to achieve PVD is very risky, especially in young patients, in whom the bonds between the vitreal cortex and the retina are strong. ${ }^{39}$ Such a vitrectomy may lead to the formation of iatrogenic holes in the retina. ${ }^{40}$ Another possible complication of vitrectomy resulting from operating in the proximity of the retina is bleeding from the retinal or uveal vessels. Incomplete
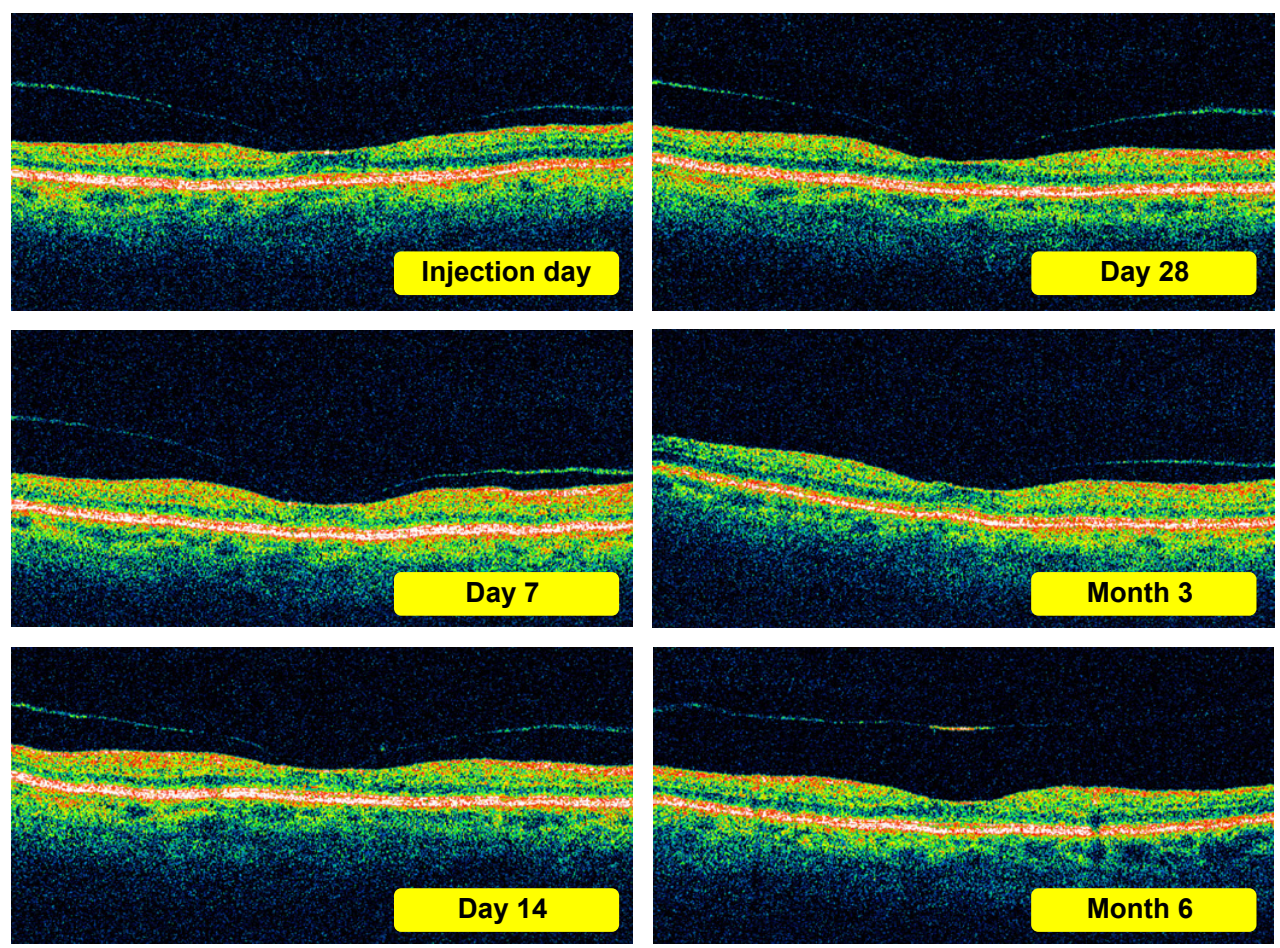

Figure 5 OCT sample pictures of patient with weak traction in the macula after injection of rTPA. (traction dissolving between 3 and 6 months). Abbreviations: OCT, optical coherence tomography; rTPA, recombinant tissue plasminogen activator. 

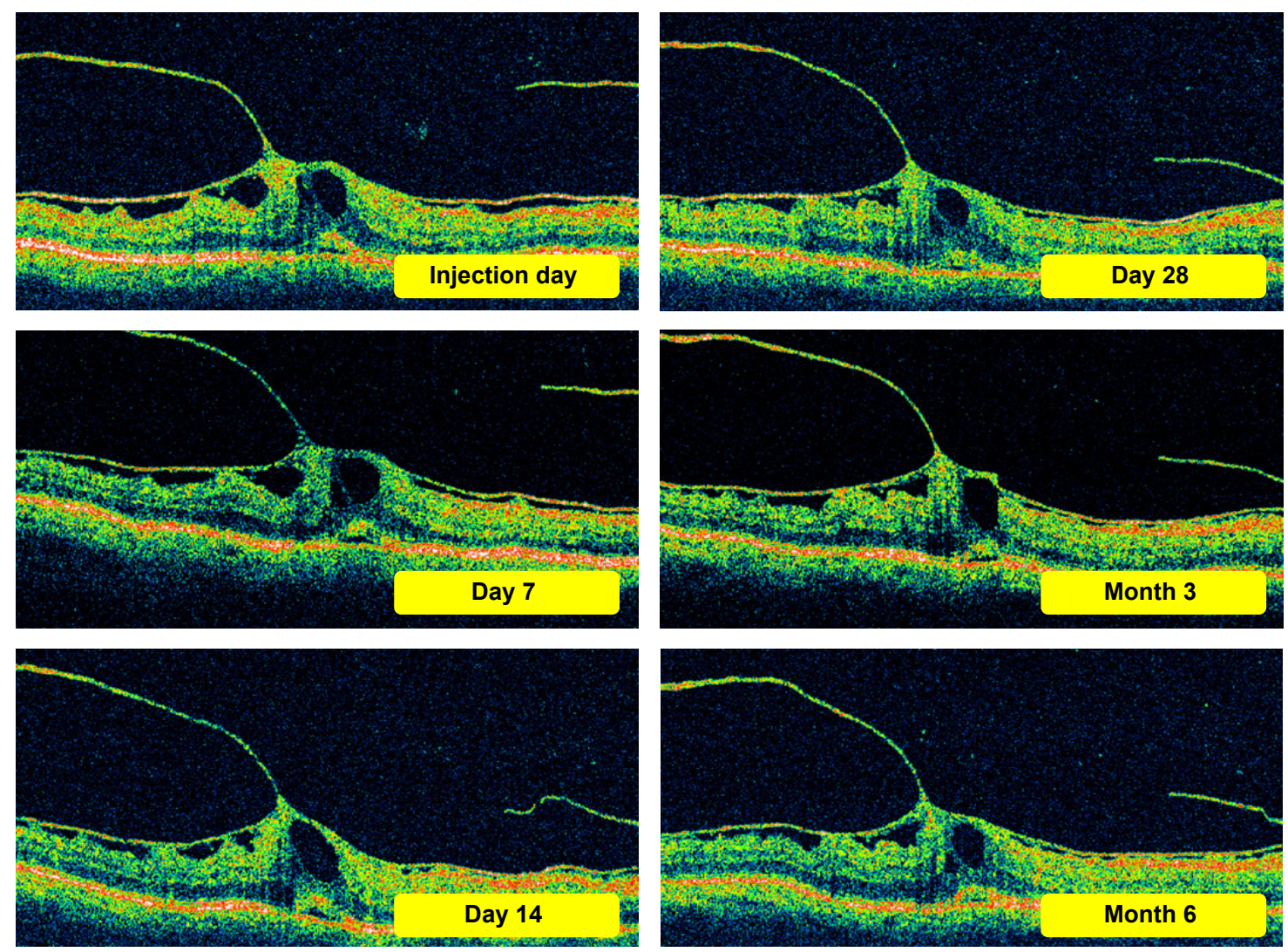

Figure 6 Examples of OCT images of a patient with strong epiretinal membrane and vitreomacular traction in which a single dose of $r$ TPA have no effect (diabetic retinopathy) Abbreviations: OCT, optical coherence tomography; rTPA, recombinant tissue plasminogen activator.

removal of the vitreous may in turn result in proliferation of membranes and fibrous tractions.

Recently, the number of posterior PPV paired with the still controversial macular peeling (ILM removal) has increased. It is known that the ILM membrane is a form of scaffolding for proliferating astrocytes ${ }^{41}$ and its removal is to prevent their re-proliferation on the surface of the retina. There is also a theory suggesting that its removal during a macular hole procedure decreases the traction tangential to the retina, improving the shape of the latter and allowing for re-mobilization. ${ }^{42}$ At present, this technique is widely used. Other research suggests that although ILM peeling during a macular hole procedure improves macular architecture, it does not improve visual acuity. ${ }^{43}$

Another group of patients in whom macular peeling is performed is that with diabetic retinopathy. Gandorfer et al ${ }^{44}$ was one of the first to observe a decrease in diffused macular edema, improvement of visual acuity, and lack of secondary ERM formation after a posterior PPV with macular peeling. The increase in number of vitrectomies performed is linked to an improvement in the diagnostics of disease within the macula but also to an increased incidence of type 2 diabetes and increased longevity of patients.
Unfortunately, posterior vitrectomy, recently increasingly paired with ILM and ERM peeling, is linked with a high risk of iatrogenic retinal damage. The removal of ILM (which is only a few microns thick, approximately 10 times thinner than a human hair) with tweezers is an extremely difficult and demanding procedure, even for an experienced surgeon. The procedure carries the risk of an iatrogenic hole in the retina and damage to RPE cells. ${ }^{45}$ Park et al ${ }^{46}$ operating 98 patients for macular hole, estimated a risk of complications in $23 \%$. The complications included creation of a hole in the retina, increase in the size of such a hole, development of a hole during the post-operative period, loss of RPE cells below the hole and inflammation of the eyeball.

The vitreous is an active component in the pathogenesis of many ophthalmological diseases, eg, VRTs, degeneration and retinal holes, hemorrhages, and pathological vessel proliferation. It is integrally bound with adjacent eye compartments. In the case of the fovea, it is of utmost importance to determine the degree of adherence between the retina and the vitreous cortex. Until very recently, without OCT such procedure was not possible as delicate membranes were difficult to observe in the stereoscopic examination. Equally difficult to monitor was progressing macular edema. 
In our own research, the mean baseline membrane thickness in the TPA group was 53.90 (9.34), while in the control group it was 49.63 (8.45). The lowest membrane thickness in the TPA group was 38 and the highest $76 \mu$. For the control group, the corresponding values were 32 and $63 \mu$, respectively.

After 6 months, the average membrane thickness in the TPA group decreased significantly (Student's $t$-test value $3.278675, P=0.0029$ ) while in the control group no statistically significant differences were seen (Student's $t$-test value 1.049412, $P=0.30277$ ). This result was confirmed in the additional ANOVA and by Tukey's test.

Moreover, from the statistical analysis of successful vitreolysis cases from both examined groups we obtained an average vitreoretinal membrane thickness at which traction dissolution can be expected of $43.67 \mu$ (7.35).

Observation of retinal thickness allowed us to conclude that this parameter decreased with time in both groups when the VRT has been dissolved.

In both TPA and control groups, in cases where VRT dissolved, macular edema decreased after 6 months.

In the TPA group traction dissolution occurred mostly in the first half of the trial period, ie, up to 3 months from the drug administration.

Calculations allowed us to conclude that in the control group there was a visual acuity loss within 6 months from the trial commencement while in the TPA group the visual acuity slightly improved.

Test results also showed that despite an increase in intraocular pressure immediately following the drug injection (day 0), this was transient and underwent normalization within 2 weeks from the drug administration.

Observing patients from the control group, ie, in the group representing a natural course of the disease (VRTs), we noticed that spontaneous VRT resolution occurred most often when at baseline such traction was thin.

At the same time the percentage distribution of the traction dissolution in the TPA group, depending on the disease, showed that traction dissolution occurred most often in patients with developing macular hole, in whom the traction was similarly thin. An additional advantage in this group was the lack of ERM. It seems the baseline thickness of the membrane participating in the VRT is an important prognostic factor for VRTS.

Only recently, with the use of modern diagnostic technology such as OCT has it been recognized how many pathological processes take place in the eye simultaneously. The DMO is frequently accompanied by taut and thickened posterior hyaloid, preretinal membrane formation, and even VMT syndrome. Etiology of the VRTs arising from the fovea is complex and depends on many factors, including age, underlying disease, its duration, concomitant diseases, history of surgical procedures, and finally on the patient's general well-being.

In the presented work, the distribution of particular diseases in both groups was very similar. The most numerous subgroup was patients with diabetic retinopathy followed by those with a history of uveitis and patients after eye injuries. Additionally, 20\% of the TPA group patients had a macular hole forming and $20 \%$ of the control group wet age-related macular degeneration. The most numerous subgroup, patients with diabetic retinopathy $(60.00 \%$ of the TPA group and $53.33 \%$ of the control group), also had the highest percentage of the ERM and present in almost $47 \%$ of both TPA and control groups. As shown by the 6-month observation of patients with VRTs in the course of diabetic retinopathy, a single injection may not be sufficient. A similar conclusion was drawn by Stalmans et $\mathrm{al}^{47}$ suggesting that in cases of VMTs better treatment effects could be achieved with several microplasmin injections.

Following the trial, we now suspect that significant prognostic factors for membrane dissolution are 1) its composition (whether it contains only fibrin or also cell/tissue elements), 2) duration, and 3) whether it is accompanied by an ERM.

It seems that in predicting the course of the disease all components of "the vitreoretinal puzzle" have to be taken into account.

The ever-increasing number of posterior PPVs used to remove membranes suggests that without the aid of surgery the problem of VRTs will remain with us for a very long time. Strong tractions, especially with accompanying ERM, can only be removed mechanically.

For years the suitability of numerous enzymes for PVD generation, ERM peeling facilitation, vitreous hemorrhage dissolution, treatment of subretinal hemorrhages, thrombi and emboli, as well as fibrinolysis of deposit build-up on artificial implants have been tested.

Taking into consideration that eye tissues are extremely sensitive even to minor metabolic changes, not all of the described enzymes have entered into everyday use.

Enzymes used for intravitreous injections should be non-toxic to the retina and should not cause cataracts or blurred vision.

\section{Conclusion}

An exemplary VRT that will most probably dissolve after a single rTPA injection is weak (with an average membrane thickness of $43.67 \mu \pm 7.35$ SD) with no coexisting ERM. 
rTPA is a safe drug. In the trial material, no complications were observed. After the dissolution of the VRT, visual acuity improves slightly. This is much better that in the control group, where vision markedly worsens with disease progression. OCT/SOCT is acceptable as the basic diagnostic procedure for selecting patients with VRTs for rTPA injections. Moreover, OCT/SOCT retinal examination provides quantitative parameters allowing monitoring of the course of the disease.

\section{Disclosure}

The authors report no conflicts of interest in this work.

\section{References}

1. Zdenek G, Kański J. Retinal Detachment: A Colour Manual of Diagnosis and Treatment. 1995.

2. Jaffe NS. Vitreous traction at the posterior pole of the fundus due to alterations in the vitreous posterior. Trans Am Acad Ophthalmol Otolaryngol. 1967;71:642-652.

3. Kański J. Clinical Ophthalmology. 2009;705. (Polish edition).

4. Brown DJ, Bishop P, Hamdi H, Kenney MC. Cleavage of structural components of mammalian vitreous by endogenous matrix metalloproteinase-2. Curr Eye Res. 1996;15:439-445.

5. William E, Smiddy MD, Ronald G, et al. Morphology, pathology and surgery of idiopathic vitreoretinal macular disorders. A review. Retina 1990;10(4):288-296.

6. Gandorfer A, Rohleder M, Kampik A. Epiretinal pathology of vitreomacular traction syndrome. Br J Ophthalmol. 2002;86(8):902-909.

7. Wang MY, Nguyen D, Hindoyan N, Sadun AA, Sebag J. Vitreo-papillary adhesion in macular hole and macular pucker. Retina. 2009;29: 644-650.

8. Cappone A. Macular surface disorders. Focal Points: Clinical Modules for Ophthalmologists. San Francisco: American Academy of Ophthalmology; 1996, module 4.

9. Williams RG, Chang S, Comaratta MR, Simoni G. Does the presence of heparin and dexamethasone in the vitrectomy infusate reduce reproliferation in proliferative vitreoretinopathy? Graefes Arch Clin Exp Ophthalmol. 1996;234(8):496-503.

10. Wiedemann P, Hilgers RD, Bauer P, Heimann K. Adjunctive daunorubicin in the treatment of proliferative vitreoretinopathy: results of a multicenter clinical trial. Daunomycin.Study Group. Am J Ophthalmol. 1998;126(4):550-559.

11. Charteris DG, Aylward GW, Wong D, et al. A randomized controlled trial of combined 5-fluorouracil and low-molecular-weight heparin in management of established proliferative vitreoretinopathy. Ophthalmology. 2004;111(12):2240-2245.

12. Wolf S, Schön V, Meier P, Wiedemann P. Silicone oil-RMN3 mixture ("heavy silicone oil") as internal tamponade for complicated retinal detachment. Retina. 2003;23(3):335-342.

13. Czajka M, Pecold K. [The use of enzymes in vitreoretinal surgery]. Zastosowanie enzymów w chirurgii witreoretinalnej. Klin Oczna. 2002;104(1):59-62. Polish.

14. Sebag J. Pharmacologic vitreolysis (editorial). Retina. 1998;18:1-3.

15. Sebag J. Is pharmacologic vitreolysis brewing? Retina. 2002;22(1):1-3.

16. Tripathi BJ, Geanon JD, Tripathi RC. Distribution of tissue plazminogen activator in human and monkey eyes. An immunohistochemical study. Ophthalmology. 1987;94(11):1434-1438.

17. Immonen I, Vaheri A, Tommila P, Sirén V. Plasminogen activation in epiretinal membranes. Graefes Arch Clin Exp Ophthalmol. 1996; 234(11):664-669.

18. Kamei M, Estafanous M, Lewis H. Tissue plasminogen activator in the treatment of vitreoretinal diseases. Semin Ophthalmol. 2000; 15(1):44-50.
19. Johnson RN, Olsen KR, Hernandez E. Intravitreal tissue plasminogen activator treatment of experimental vitreous haemorrhage. Arch. Ophthalmol. 1989;107:891-904.

20. Heras-Mulero H, García-Gómez PJ, Sádaba-Echarri LM, SalinasAlamán A, García-Layana A. Traumatic submacular hemorrhage treated with rt-PA and SF6. Arch Soc Esp Oftalmol. 2007;82(8):517-520.

21. Krepler K, Kruger A, Tittl M, Stur M, Wedrich A. Intravitreal injection of tissue plasminogen activator and gas in subretinal hemorrhage caused by age-related macular degeneration. Retina. 2000;20(3):251-256.

22. Chen SN, Ho CL, Kuo YH, Ho JD. Intravitreous tissue plasminogen activator injection and pneumatic displacement in the management of submacular hemorrhage complicating scleral buckling procedures. Retina. 2001;21(5):460-463.

23. Chiselită D, Antohi I, Cionca D, Medvichi R, Cimpoeşu D. The use of tissue plasminogen activator in the post-operative treatment of fibrinoid uveitis. Oftalmologia. 2006;50(2):68-72.

24. Oficjalska-Młyńczak J, Marek J, Zając-Pytrus H, Niżankowska M, Koziorowska M. Tkankowy aktywator plazminogenu w leczeniu błon włóknikowych po operacji zaćmy. Klin Oczna. 1996;98(6):423-425.

25. Murakami T, Takagi H, Kita M, et al. Intravitreal tissue plasminogen activator to treat macular edema associated with branch retinal vein occlusion. Am J Ophthalmol. 2006;142(2):318-320.

26. Weizer JS. Fekrat S. Intravitreal tissue plasminogen activator for the treatment of central retinal vein occlusion. Ophthalmic Surg Lasers Imaging. 2003;34(4):350-352.

27. Kertes PJ, Peyman GA, Chou F, Meffert S, Conway MD. The use of tissue plasminogen activator in silicone oil-filled eyes. Can J Ophthalmol. 1998;33(1):28-29.

28. MacCumber MW, McCuen BW 2nd, Toth CA, Ferrone PJ, Jaffe GJ. Tissue plasminogen activator for preserving inferior peripheral iridectomy patency in eyes with silicone oil. Ophthalmology. 1996;103(2): 269-273.

29. Zalta AH, Sweeney CP, Zalta AK, Kaufman AH. Intracameral tissue plasminogen activator use in a large series of eyes with valved glaucoma drainage implants. Arch Ophthalmol. 2002;120(11):1487-1493.

30. Tsui I, Airiani S, Wen A, El-Sawy T, Fine HF, Maris PJ. Intravitreal injection of tissue plasminogen activator as treatment for an occluded pars plana glaucoma tube. Clin Ophthalmol. 2009;3:91-93.

31. Hesse L, Nebeling B, Schroeder B, Heller G, Kroll P. Induction of posterior vitreous detachment in rabbits by intravitreal injection of tissue plasminogen activator following cryopexy. Exp Eye Res. 2000;70(1):31-39.

32. Sonoda KH, Sakamoto T, Enaida H, et al. Residual vitreous cortex after surgical posterior vitreous separation visualized by intravitreous triamcinolone acetonide. Ophthalmology. 2004;111:226-230.

33. Tachi N, Ogino N. Vitrectomy for diffuse macular edema in cases of diabetic retinopathy. Am J Ophthalmol. 1996;122:258-260.

34. Kiryu J, Kita M, Tanabe T, et al. Pars plana vitrectomy for cystoid macular edema secondary to sarcoid uveitis. Ophthalmology. 2001;108: 1140-1144.

35. Tachi N, Hashimoto Y, Ogino N. Vitrectomy for macular edema combined with retinal vein occlusion. Doc Ophthalmol. 1999;97:465-469.

36. Stefansson E, Novack RL, Hatchell DL. Vitrectomy prevents retinal hypoxia in branch retinal vein occlusion. Invest Ophthalmol Vis Sci. 1990; 31:284-289.

37. Oficjalska-Mlynczak J, Zajac-Pytrus H, Marek J, Nizankowska MH. Treatment of subretinal macular hemorrhages with intravitreous injections of tissue plasminogen activator and SF6 gas. Klin Oczna. 2003; 105(3-4):140-146.

38. Jaffe G, Green G, Abrams G. Stability of recombinant tissue plasminogen activator. Am J Ophthalmol. 1989;108:90-91.

39. Sebag J. Age-related changes in human vitreous structure. Graefe's Arch Clin Exp Ophthalmol. 1987;225:89-93.

40. Aznabayev MT, Aznabayev RA, Kazakbayev AG, Iskandartev RH. Vitreous surgery in children. Doc Ophthalmol. 1994;86:381-386.

41. Kamei M, Misono K, Lewis H. A study of the ability of tissue plasminogen activator to diffuseinto the subretinal space after intravitreal injection in rabbits. Am J Ophthalmol. 1999;128(6):739-746. 
42. Rice TA. Internal limiting membrane removal in surgery for fullthickness macular holes. In: Madreperla SA, Mc Cuen BW II, editors. Macular Hole, Pathogenesis, Diagnosis and Treatment. Boston: Butterworth Heinemann; 1998:125-146.

43. Castro Navarro J, Gonzalez-Castano C. Macular hole surgery with and without internal limiting membrane peeling. Arch Soc Esp Oftalmol. 2003;78(3):159-164.

44. Gandorfer A, Elisabeth M, Ulbig MW, Kampik A. Resolution of diabetic macular edema after surgical removal of the posteriori hyaloid and the inner limiting membrane. Retina. 2000;20:126-133.
45. Christensen UC, Kroyer K, Sander B, Jorgensen TM, Larsen M, la Cour M. Macular morphology and visual acuity after macular hole surgery with or without internal limiting membrane peeling. $\mathrm{Br} J$ Ophthalmol. 2010;94(1):41-47.

46. Park SS, Marcus DM, Duker JS, et al. Posterior segment complications after vitrectomy for macular hole. Ophthalmology. 1995;102(5):775-781.

47. Stalmans P, Delaey C, Marc D, et al. Intravitreal injection of microplasmin for treatment of vitreomacular adhesion. Results of a prospective, randomized, sham-controlled phase II trial (The MIVI-IIT Trial). Retina. 2010;30:1122-1127.

\section{Publish your work in this journal}

Drug Design, Development and Therapy is an international, peerreviewed open-access journal that spans the spectrum of drug design and development through to clinical applications. Clinical outcomes, patient safety, and programs for the development and effective, safe, and sustained use of medicines are a feature of the journal, which has also been accepted for indexing on PubMed Central. The manuscript management system is completely online and includes a very quick and fair peer-review system, which is all easy to use. Visit http://www.dovepress.com/testimonials.php to read real quotes from published authors.

Submit your manuscript here: http://www.dovepress.com/drug-design-development-and-therapy-journal 